\title{
List of Maps
}

Map I.I. The Southwest Pacific and Queensland 4

Map 4.I. The New Georgia Group, Solomon Islands $\quad 170$

Map 5.I. Eastern New Guinea circa 1930 
This page intentionally left blank 